\title{
Bifocal Synchronous Adenocarcinoma of the Transverse Colon: Case Report
}

Christel Marie Laleye*, Setondji Gilles Roger Attolou, Dansou Gaspard Gbessi, Elohonnan Wilfried Gandji, Yakoubou Imorou, Habib N'domè Natta N'tcha, Kuassi Delphin Mehinto

Hubert KoutouKou Maga, University Teaching Hospital Center, Cotonou, Bénin

DOI: $10.36347 /$ sasjs.2020.v06i10.006

| Received: 30.09 .2020 | Accepted: 16.10.2020 | Published: 23.10.2020

*Corresponding author: Christel Marie Lalèyè

\section{Abstract}

Introduction: Multiple primary colon tumors are rare and pose significant problems in diagnosis and treatment. We report a case of synchronous transverse colon tumor discovered during management of an occlusion. Observation: A 56-year old patient was admitted to the emergency ward for the management of acute intestinal obstruction. During the surgery, we discovered a bifocal colon tumor: 01 stenosing $5 \mathrm{~cm}$ tumor located at the left colic angle and 01 nonstenosing $3 \mathrm{~cm}$ tumor located $5 \mathrm{~cm}$ from the right colonic angle. We realized enterotomy of the terminal ileum $15 \mathrm{~cm}$ from the ileo-cecal crossroads; an ileostomy on a rod in right iliac fossa. The postoperative extension assessment found absence of secondary hepatic, peritoneal, pulmonary and bone lesions. Via Colonoscopy, we found bifocal stenosing tumor of the transverse colon classified T4N0M0. A month and a half later, he underwent a segmental colectomy removing the transverse colon and the two colonic angles with colo-colonic anastomosis and additional appendectomy. The surgery management was simple. Conclusion: Synchronous and consecutive (metachronic) development of two or more primary adenocarcinomas accounts for 3-5\% of colorectal cancer cases. It remains important to detect these synchronous tumors at the time of surgery although a third of lesions may be missed this way. The choice of the type of surgery remains controversial, especially for multiple colorectal tumors.

Keywords: Colon tumors, bifocal, adenocarcinoma.

Copyright $\odot 2020$ The Author(s): This is an open-access article distributed under the terms of the Creative Commons Attribution 4.0 International License (CC BY-NC 4.0) which permits unrestricted use, distribution, and reproduction in any medium for non-commercial use provided the original author and source are credited.

\section{INTRODUCTION}

Multiple primary colon tumors are rare and pose significant problems in diagnosis and treatment. Detection of synchronous tumor site requires a change in treatment method. Synchronous adenocarcinomas can be two or more, detected either before, during or in a period of 6 months after surgery. They must be at least $4 \mathrm{~cm}$ apart and they should not consist of submucosal spread or satellite damage to each other [1]. In any other words, they are considered regional or metastatic lesions. We report a case of synchronous transverse colon tumor discovered during management of an occlusion.

\section{OBSERVATION}

A 56-year old patient with a history of chronic constipation, admitted to the emergency for the management of acute intestinal obstruction; in whom the questioning and physical examination revealed:

- A start dating 20 days before admission.
- A progressive onset of pain, initially localized in the right para-umbilical region and secondarily generalized.

- A systemic inflammatory response syndrome (temperature: $38.3^{\circ} \mathrm{C}$; pulse: 98ppm; FR: 22 cycles per min).

- An occlusive syndrome: stopping of stool and gases; diffuse abdominal meteorism and late bilious then fecaloid vomiting of food.

- Rectal examination without particularities.

An unprepared $\mathrm{x}$-ray of the abdomen finds hail-like hydro-aeric levels (wider than high); an aerocoly of the left colon and an unventilated rectum. The diagnosis of acute febrile bowel obstruction on probable colonic tumor was suggested and the indication for surgery was made. During the surgery we discovered:

- A significant dilation of the small intestine,

- A bifocal colon tumor: 01 stenosing $5 \mathrm{~cm}$ tumor located at the left colic angle and 01 non-stenosing $3 \mathrm{~cm}$ tumor located $5 \mathrm{~cm}$ from the right colonic angle, 
- An absence of peritoneal carcinoma,

We realized:

- Enterotomy of the terminal ileum $15 \mathrm{~cm}$ from the ileo-cecal crossroads,

- An ileostomy on a rod in right iliac fossa,

- Washing and draining of the abdominal cavity. The postoperative treatment was straightforward with a functional ileostomy on the 3rd day and discharge from hospital on the 8th day.

The postoperative extension assessment found:

- On CT: bifocal and synchronous colonic tumor infiltration located at the left colonic angle and transverse colon with colonic distension between the two tumor processes. Absence of secondary hepatic, peritoneal, pulmonary and bone lesions.
- Via Colonoscopy: bifocal stenosing tumor of the transverse colon classified T4NOM0.

A month and a half later, he underwent a segmental colectomy removing the transverse colon and the two colonic angles with end-to-end colo colonic anastomosis and additional appendectomy (Figures 1, 2 and 3). The post surgery follow-up was simple with exeation on 8th day.

Pathological examination concluded in two low-grade Lieberkhunian adenocarcinomas infiltrating the serosa without a colloid component. No vascular embolus. Presence of a mucous colloid contingent estimated at $5 \%$. No vascular embolus. The limits of longitudinal resections were healthy. The tumors were classified as pT4N0. We closed the ileostomy 01 month postoperatively. We opted for neoadjuvant chemotherapy, but the patient opposed it. The one-year follow-up did not find any secondary thoracoabdominal lesions.

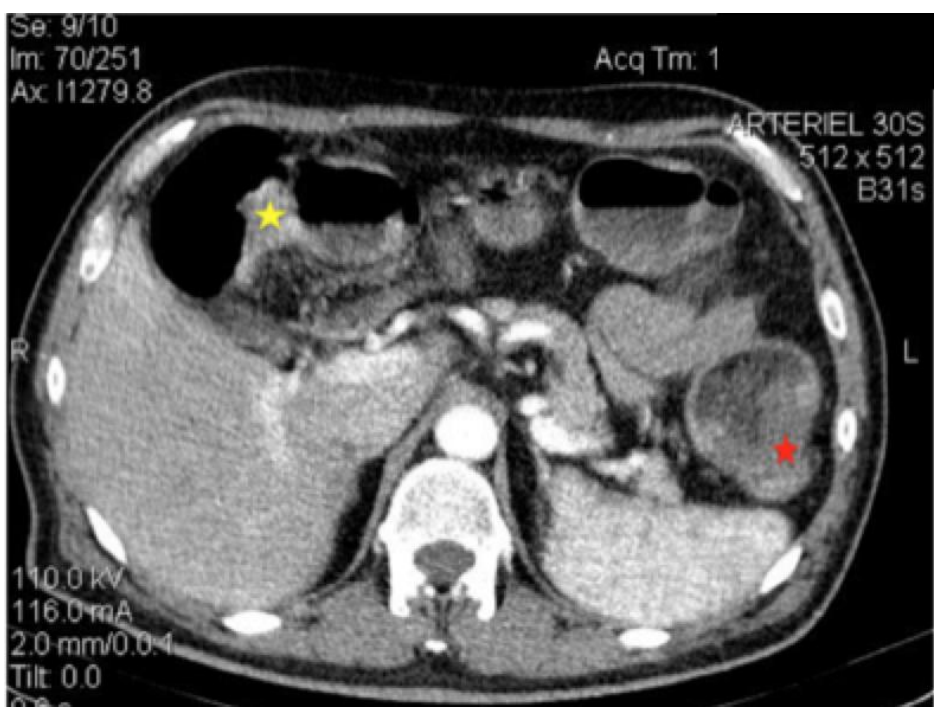

Fig-1: Abdominal CT scan showing the two locations of the tumor

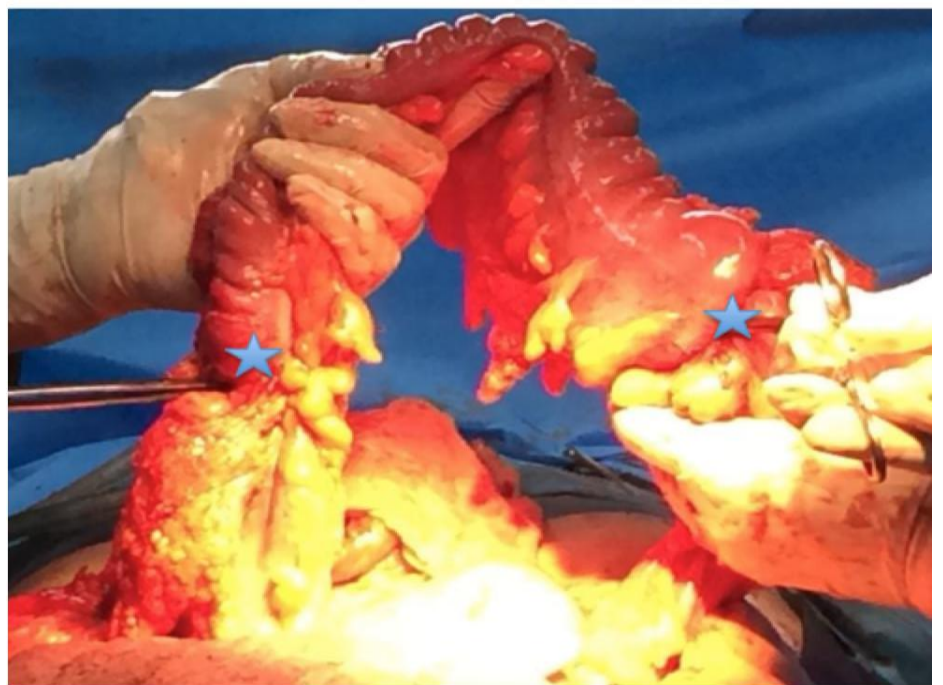

Fig-2: Intraosurgery image of the bifocal colonic tumor 


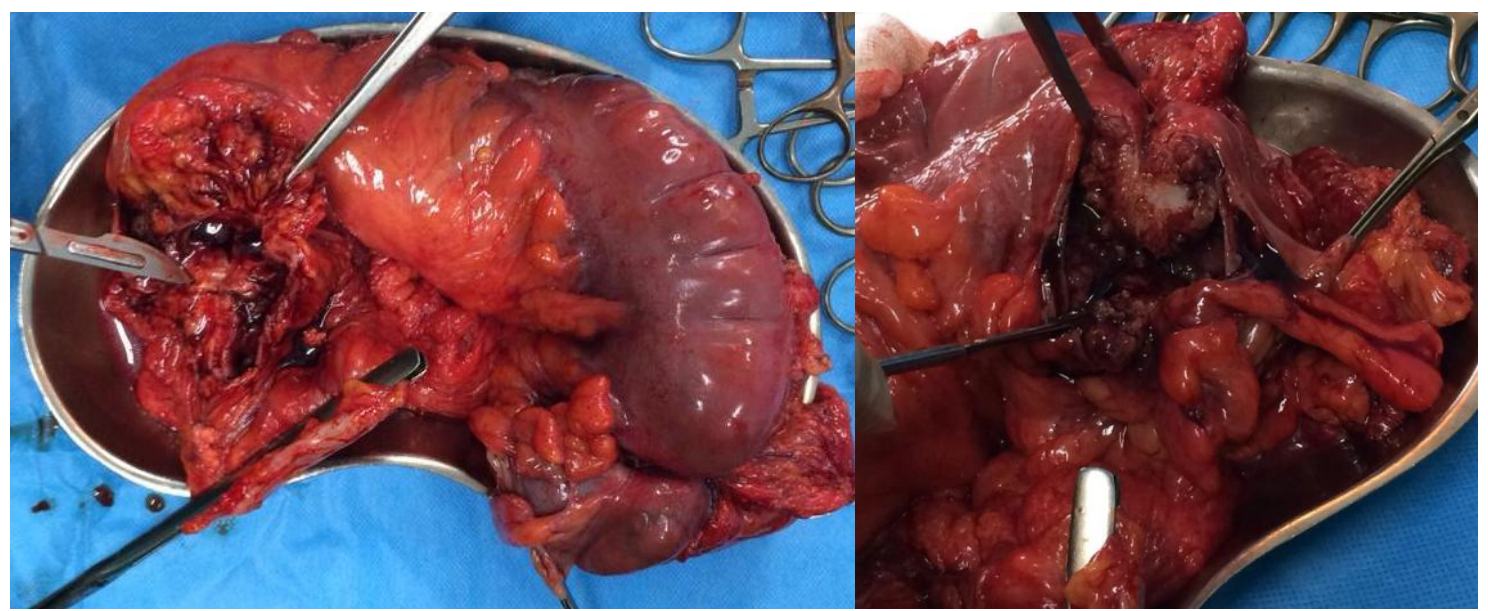

Fig-3: Images of colonic tumors after opening

\section{DISCUSSION}

The first multiple adenocarcinomas of the colon were described in 1880 by Czerney [1]. Synchronous and consecutive (metachronic) development of two or more primary adenocarcinomas account for 3-5\% of colorectal cancer cases [1-3]. An incidence of up to $12.4 \%$ has been reported by some authors $[1,4]$. The preoperative diagnosis of multiple synchronous colorectal carcinomas remains difficult and the second site is often overlooked, although the available techniques have been improved considerably (barium enema and colonoscopy). Identifying a tumor that justifies clinical symptoms usually suspends further investigation [5]. It remains important to detect these synchronous tumors at the time of surgery although a third of lesions may be missed this way [6, 7]. Nevertheless, it is crucial to palpate the entire colon and rectum during surgery in order to detect any missing lesions. The majority of colorectal cancers occur distally, which limits the number of patients in whom the intestine near the primary lesion can be examined preoperatively [2]. It is suggested that all patients should have a pre- or postoperative colonoscopy because synchronous impalpable tumors have been reported in $34 \%$ of resected cases $[6,7]$.

The choice of the type of surgery remains controversial, especially for multiple colorectal tumors. Some authors propose radical operations, such as total colectomy with ileorectal anastomosis [8], in order to remove all tumors and any coexisting synchronous polyps. Other authors $[9,10]$ recommend a more conservative approach for elderly patients and radical surgery for patients under 60 years of age with nonmetastatic disease. In light of these recommendations, we could assume that our support is deviating from it. However, the extension assessment carried out in the post surgery did not find any metastases on the CT scan and the colonoscopy did not identify any other colonic location or any polyp. In view of this, the choice of conservative treatment is justified.
Stage II (T3-T4-N0) colonic cancers form a very heterogeneous group from an anatomopathological point of view which is associated with a very heterogeneous prognosis with overall 5-year survival rates of $87.5 \%$ in the event of stage IIa and $58.4 \%$ for stage IIc [11]. The results reported on the effect of adjuvant chemotherapy in the treatment of stage II colonic cancers are also very heterogeneous and few specific trials have been conducted to attempt to answer the question [12]. Regular postoperative follow-up of patients with colorectal cancer will reduce the risk of metachronous carcinoma. Several studies have shown no significant difference in survival between multiple and single colorectal cancers $[13,14]$.

\section{CONCLUSION}

Synchronous colon tumors are relatively rare but with an underestimated incidence. The diagnosis is most often made during the surgery. The treatment and prognosis are not fundamentally different from that of a single tumor. We presented a case of synchronous bifocal adenocarcinoma of the transverse colon, process by an atypical segmental colectomy and whose evolution was simple.

\section{REFERENCES}

1. Cunliffe WJ, Hasleton PS, Tweedle DEF, Schofield PF. Incidence of synchronous and metachronous colorectal carcinoma. Br J Surg. déc 1984;71(12):941-3.

2. Papadopoulos V, Michalopoulos A, Basdanis G, Papapolychroniadis K, Paramythiotis D, Fotiadis $\mathrm{P}$. Synchronous and metachronous colorectal carcinoma. Tech Coloproctology. nov 2004;8(S1):97-100.

3. Chen HS, Sheen-Chen SM. Synchronous and « early » metachronous colorectal adenocarcinoma: analysis of prognosis and current trends. Dis Colon Rectum. août 2000;43(8):1093-9.

4. Welch JP. Multiple colorectal tumors. Am J Surg. août 1981; 142(2):274-80.

5. Tziris N, Dokmetzioglou J, Giannoulis K, Kesisoglou I, Sapalidis K, Kotidis E. Synchronous 
and metachronous adenocarcinomas of the large intestine. Hippokratia. 2008; 12(3):150-2.

6. Ueno M, Muto T, Oya M, Ota H, Azekura K, Yamaguchi T. Multiple primary cancer: an experience at the Cancer Institute Hospital with special reference to colorectal cancer. Int $\mathrm{J}$ Clin Oncol. 1 juin 2003;8(3):162-7.

7. Scaife CL, Rodriguez-Bigas MA. Lynch Syndrome: Implications for the Surgeon. Clin Colorectal Cancer. août 2003;3(2):92-8.

8. Rosenthal I. Prognostic and therapeutic implications of polyps in metachronous colic carcinoma. J Am Med Assoc. 2 janv 1960; 172(1):37.

9. Wright HK, Thomas WH, Cleveland JC. The low recurrence rate of colonic carcinoma in ileocolic anastomoses. Surg Gynecol Obstet. nov 1969; 129(5):960-2.

10. Tsantilas D, Ntinas A, Petras P, Zambas N, Al Mogrambi S, Frangandreas G. Metachronous colorectal adenocarcinomas. Tech Coloproctology. nov 2004;8(S1):202-4.
11. Gunderson LL, Jessup JM, Sargent DJ, Greene FL, Stewart AK. Revised TN categorization for colon cancer based on national survival outcomes data. J Clin Oncol Off J Am Soc Clin Oncol. 10 janv 2010; 28(2):264-71.

12. Mamounas E, Wieand S, Wolmark N, Bear HD, Atkins JN, Song K. Comparative Efficacy of Adjuvant Chemotherapy in Patients With Dukes' B Versus Dukes' C Colon Cancer: Results From Four National Surgical Adjuvant Breast and Bowel Project Adjuvant Studies (C-01, C-02, C03, and C-04). J Clin Oncol. mai 1999;17(5):13491349.

13. Kaibara N, Koga S, Jinnai D. Synchronous and metachronous malignancies of the colon and rectum in Japan with special reference to a coexisting early cancer. Cancer. 1 nov 1984; 54(9):1870-4.

14. Agrez MV, Ready R, Ilstrup D, Beart RW. Metachronous colorectal malignancies: Dis Colon Rectum. sept 1982; 25(6):569-74. 